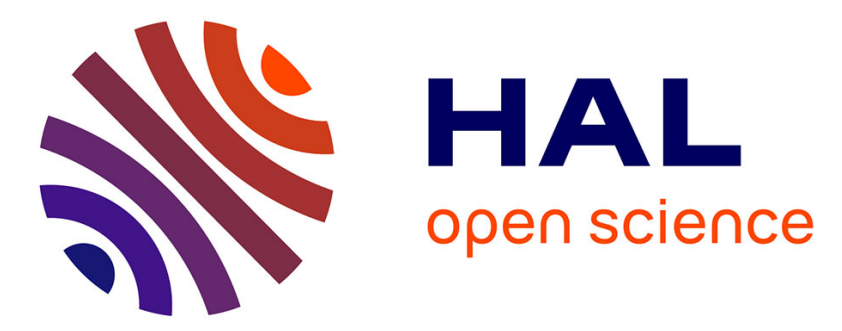

\title{
Synergistic anti-fouling and bactericidal poly(ether ether ketone) surfaces via a one-step photomodification
} Sytze Buwalda, Stijn Rotman, David Eglin, Fintan Moriarty, Audrey Bethry, Xavier Garric, Olivier Guillaume, Benjamin Nottelet

\section{To cite this version:}

Sytze Buwalda, Stijn Rotman, David Eglin, Fintan Moriarty, Audrey Bethry, et al.. Synergistic antifouling and bactericidal poly(ether ether ketone) surfaces via a one-step photomodification. Materials Science and Engineering: C, 2020, 111, pp.110811. 10.1016/j.msec.2020.110811 . hal-03095870

\section{HAL Id: hal-03095870 https://hal.science/hal-03095870}

Submitted on 4 Jan 2021

HAL is a multi-disciplinary open access archive for the deposit and dissemination of scientific research documents, whether they are published or not. The documents may come from teaching and research institutions in France or abroad, or from public or private research centers.
L'archive ouverte pluridisciplinaire HAL, est destinée au dépôt et à la diffusion de documents scientifiques de niveau recherche, publiés ou non, émanant des établissements d'enseignement et de recherche français ou étrangers, des laboratoires publics ou privés. 


\section{Synergistic Anti-fouling and Bactericidal}

\section{Poly(ether ether ketone) Surfaces via a One-step}

\section{Photomodification}

Sytze Buwalda, ${ }^{a \neq 1}$ Stijn Rotman, ${ }^{b{ }^{\ddagger}}$ David Eglin, ${ }^{b}$ Fintan Moriarty, ${ }^{b}$ Audrey Bethry, ${ }^{a}$, Xavier Garric, ${ }^{a}$ Olivier Guillaume, ${ }^{b}{ }^{2}$ Benjamin Nottelet ${ }^{a}$

a IBMM, University of Montpellier, CNRS, ENSCM, 15 avenue Charles Flahault, 34093 Montpellier, France

${ }^{\mathrm{b}}$ AO Research Institute Davos, Clavadelerstrasse 8, 7270 Davos Platz, Switzerland

${ }^{\mathrm{c}}$ Department of Biomaterials Science and Technology, Faculty of Science and Technology, Technical Medical Centre, University of Twente, Enschede, The Netherlands

${ }^{\ddagger}$ These authors contributed equally to the manuscript.

* Corresponding authors: Olivier Guillaume (olivier.guillaume@tuwien.ac.at) and Benjamin Nottelet (benjamin.nottelet@umontpellier.fr)

1 Present address: MINES ParisTech, PSL Research University, Center for Materials Forming (CEMEF), UMR CNRS 7635, CS 10207, 06904 Sophia Antipolis, France

${ }^{2}$ Present address: Technical University Vienna, Additive Manufacturing Technologies (AMT) group, Getreidemark 9/E 308, 1060 Vienna, Austria 


\begin{abstract}
Implants of poly(ether ether ketone) (PEEK) are gaining importance in surgical bone reconstruction of the skull. As with any implant material, PEEK is susceptible to bacterial contamination and occasionally PEEK implants were removed from patients because of infection. To address this problem, a combination of anti-fouling and bactericidal polymers are grafted onto PEEK. The originality is that anti-fouling (modified poly(ethylene glycol)) and bactericidal (quaternized poly(dimethylaminoethyl acrylate)) moieties are simultaneously and covalently grafted onto PEEK via UV photoinsertion. The functionalized PEEK surfaces are evaluated by water contact angle measurements, FTIR, XPS and AFM. Grafting of anti-fouling and bactericidal polymers significantly reduces Staphylococcus aureus adhesion on PEEK surfaces without exhibiting cytotoxicity in vitro. This study demonstrates that grafting combinations of anti-fouling and bactericidal polymers synergistically prevents bacterial adhesion on PEEK implants. This approach shows clinical relevance as grafting is rapid, does not modify PEEK properties and can be conducted on pre-formed implants.
\end{abstract}

Keywords: poly(ether ether ketone) (PEEK), anti-fouling polymers, bactericidal polymers, surface modification, aryl-azide photoinsertion

\title{
1. Introduction
}

The introduction of poly(ether ether ketone) (PEEK), almost two decades ago, had a tremendous impact in orthopedics $[1,2]$. Due to its excellent biocompatibility, radiolucency, inertness, strength and processability, PEEK based implants are overtaking many other materials such as titanium alloys [3]. Importantly, PEEK prostheses can easily be manufactured with modern 3D printing 
technology, using data originating from the patient's computed tomography scan. As a consequence, the fabrication of customized PEEK patient implants for craniomaxillo-facial reconstruction has been recently reported with promising results in terms of aesthetics and biological functionality [4-6]. Such patient specific implants made of PEEK constitute an excellent option for the reconstruction of large and complex defects and represent an emerging alternative for titanium implants. Due to the aforementioned advantages, the use of PEEK implants is currently spreading to other surgical fields, including spinal fusion (PEEK PREVAIL ${ }^{\mathrm{TM}}$ from Medtronic) [7], stabilization of osteotomy (iBalance ${ }^{\circledR}$ HTO implants and anchors from Arthrex) [8], intra-medullar nails (composite carbon-PEEK biomaterial Carbofix from Orthopedics) [9] or dental implants (commercialized by IQ Implant) [10] to mention only some of them.

Unfortunately, contamination of PEEK implants by bacteria is still a recurrent complication and source of printed implant failure, even upon administration of local and systemic anti-bacterial therapy [4-6]. For this reason, several researchers have focused their attention on the chemical modification of the surface of PEEK implants to endow them with anti-infective properties. Two main strategies have been used to prevent implant-related infection: (1) minimizing the bacterial attachment or (2) killing bacteria present on the surface of the implant. In the first category, Ishihari et al. grafted a coating of poly(2-methacryloyloxyethyl phosphorylcholine) (PMPC), a highly hydrophilic polymer, onto the surface of PEEK via photo-induced graft polymerization of MPC [11] or via aryl-azide UV photoinsertion of PMPC [12]. It was found that the increased surface wettability of PEEK-PMPC ( $<10^{\circ}$ for PEEK-PMPC compared to $90^{\circ}$ for untreated PEEK) offered a certain degree of protection in vitro against $E$. coli adhesion [13]. PEEK has also been endowed with anti-fouling properties by UV irradiation-assisted grafting of poly(octafluoropentyl methacrylate) [14] and poly(oligo(ethylene glycol) methacrylate) [15]. However, the efficacy of 
these 'passive' anti-fouling coatings on the surface of medical devices can be questioned, as it generally only decreases partially and temporarily the number of bacteria attaching to the surface of the implants. Consequently, several research teams have conferred 'active' bactericidal protection to PEEK, for example by coating the surface with silver containing formulations [16] or by mixing PEEK granules with silver before implant manufacture [17]. However, the use of silver-based medical devices has several disadvantages, including the development of resistance by bacteria [18], possible leakage of silver nanoparticles at toxic levels $[19,20]$, as well as increased surface roughness, which may favor bacterial adhesion [21]. Furthermore, over the course of exposure and due to the accumulation of bacterial debris, the bactericidal groups can be masked and become ineffective against the subsequent bacteria colonizing the implants [22]. In this respect, conferring dual-functionality by grafting a combination of an anti-fouling polymer and a bactericidal agent could be a potent combination to prevent PEEK implant infection. In order to have a clinical impact, the grafting of those moieties must be feasible onto the surface of existing pre-formed implants, must be rapid and should not alter the physico-chemical and biological properties of the PEEK. Grafting should also be feasible without pre-functionalization or preactivation steps.

In this respect, the use of aryl-azide groups is an attractive approach [23], as they are converted into reactive nitrene intermediates upon UV irradiation that can form covalent bonds by insertion into carbon-hydrogen bonds which are present in most polymer substrates. This prompted us to explore a new strategy for the prevention of PEEK implant infection by grafting a combination of anti-fouling polymers as well as bactericidal polymers onto PEEK using aryl-azide UV photoinsertion. 
In this manuscript, we first describe the synthesis and characterization of aryl-azide containing anti-fouling poly(ethylene glycol) (PEG) and bactericidal quaternized poly(dimethylaminoethyl acrylate) (P(qDMAEMA)) polymers. Subsequently, we discuss their covalent grafting onto PEEK via UV photoinsertion. Lastly, we demonstrate the anti-fouling and bactericidal potential of the modified PEEK surfaces during in vitro exposure to planktonic bacteria and validate the absence of leachable toxic compounds from the final biomaterials on fibroblasts. To the best of our knowledge, this is the first report describing a one-step chemical functionalization of PEEK with synergistically operating anti-fouling and bactericidal polymers. This chemical approach is of great interest as it can potentially be applied not only to PEEK, but also to the vast majority of other polymer-based implants as it requires only substrates with available carbon-hydrogen bounds.

\section{Experimental section}

\subsection{Materials}

4-Azidobenzoic acid was purchased from TCI Europe (Zwijndrecht, The Netherlands). 4Aminophenol hydrochloride, sodium nitrite, sodium azide, 2-cyano-2-propyl benzodithioate (CPDB), 2,2'-azobis(2-methylpropionitrile) (AIBN), 2-(dimethylamino)ethyl methacrylate (DMAEMA), 1-iododecane, $D L$-1-amino-2-propanol, methacryloyl chloride, phosphate buffered saline (PBS), 4-(dimethylamino)pyridine (DMAP), p-toluenesulfonic acid, triethylamine (TEA), 4,4'-azobis(4-cyanopentanoic acid) (ABCPA), poly(ethylene glycol) methyl ether $\left(M_{n}=2000\right.$, 5000 and $12000 \mathrm{~g} \mathrm{~mol}^{-1}$, mPEG2K, mPEG5K and mPEG12K, respectively) and dicyclohexylcarbodiimide (DCC) were all obtained from Sigma-Aldrich (St-Quentin Fallavier, France). 4-Azidophenol [24], 2-hydroxypropyl methacrylamide (HPMA) [25] and 4- 
(dimethylamino)pyridinium-4-toluenesulfonate (DPTS) [26] were synthesized as reported previously. Dichloromethane (DCM) and TEA were dried over calcium hydride and potassium hydroxide, respectively, and distilled prior to use. Tryptic soy agar (TSA) plates were purchased from Oxoid (Wesel, Germany) and were checked for sterility by overnight incubation at $37^{\circ} \mathrm{C}$. Tryptic soy broth (TSB) was bought from Oxoid (Basingstoke Hampshire, England). 2-Propanol was purchased from Roth (Karlsruhe, Germany). Two bacterial strains were used in this study, Staphylococcus aureus (S. aureus, NCTC 12973) and Escherichia coli (E. coli, NCTC 12441). LIVE/DEAD ${ }^{\circledR}$ BacLight $^{\mathrm{TM}}$ Bacterial Viability Kit L13152 was purchased from Molecular Probes (Leiden, the Netherlands). Pooled human serum from two donors (non-heat inactivated) was collected and kindly donated by the Blutspendedienst SRK Graubünden.

\subsection{Synthesis}

4-azidophenyl methacrylate

4-Azidophenyl methacrylate (4-APM) was synthesized following a previously reported procedure [27]. Detailed synthetic procedure and ${ }^{1} \mathrm{H}$ NMR peaks assignments are provided in the supplementary data.

\section{(PEG-XK)-P(HPMA-N 3 ) diblock copolymers}

(PEG-XK)-P(HPMA-N ${ }_{3}$ ) diblock copolymers were synthesized in 3 steps. (PEG-2K) 2 -ABCPA, $(\mathrm{PEG}-5 \mathrm{~K})_{2}$-ABCPA and (PEG-12K) $)_{2}$-ABCPA macro-initiators were first synthesized starting from $\mathrm{mPEG} 2 \mathrm{~K}, \mathrm{mPEG} 5 \mathrm{~K}$ and $\mathrm{mPEG} 12 \mathrm{~K}$, respectively according to a procedure previously reported [28]. The detailed synthetic procedure and ${ }^{1} \mathrm{H}$ NMR peaks assignments are provided in the supplementary data. 
SEC: $M_{n} 3800 \mathrm{~g} \mathrm{~mol}^{-1}, \oslash 1.34\left((\mathrm{PEG}-2 \mathrm{~K})_{2}-\mathrm{ABCPA}\right) ; M_{n} 12700 \mathrm{~g} \mathrm{~mol}^{-1}, Ð 1.17\left((\mathrm{PEG}-5 \mathrm{~K})_{2^{-}}\right.$ ABCPA) ; SEC: $M_{n} 20800 \mathrm{~g} \mathrm{~mol}^{-1}, Ð 1.24$ ((PEG-12K)2-ABCPA).

(PEG-2K)-P(HPMA), (PEG-5K)-P(HPMA) and (PEG-12K)-P(HPMA) diblock copolymers were then synthesized starting from (PEG-2K) $)_{2}-\mathrm{ABCPA}$, (PEG-5K) ${ }_{2}-\mathrm{ABCPA}$ and $(\mathrm{PEG}-12 \mathrm{~K})_{2}-$ ABCPA, respectively [28]. The detailed synthetic procedure and ${ }^{1} \mathrm{H}$ NMR peaks assignments are provided in the supplementary data.

SEC: $M_{n} 4900 \mathrm{~g} \mathrm{~mol}^{-1}, \oslash 1.24$ ((PEG-2K)-P(HPMA)); $M_{n} 8800 \mathrm{~g} \mathrm{~mol}^{-1}, \oslash 1.34$ ((PEG-5K)P(HPMA)); $M_{n} 22600 \mathrm{~g} \mathrm{~mol}^{-1}, \oslash 1.07$ ((PEG-12K)-P(HPMA)).

Finally, (PEG-2K)-P(HPMA-N $\left.{ }_{3}\right), \quad(\mathrm{PEG}-5 \mathrm{~K})-\mathrm{P}\left(\mathrm{HPMA}_{3}\right)$ and $\quad(\mathrm{PEG}-12 \mathrm{~K})-\mathrm{P}\left(\mathrm{HPMA}_{3} \mathrm{~N}_{3}\right)$ diblock copolymers were synthesized starting from (PEG-2K)-P(HPMA), (PEG-5K)-P(HPMA) and (PEG-12K)-P(HPMA), respectively by esterification of P(HPMA) units with 4-azidobenzoic acid using DMAP as catalyst and dry DMF as solvent. The details of this last synthetic procedure are provided in the supplementary data. The typical ${ }^{1} \mathrm{H}$ NMR peaks assignments of this new family of copolymers are provided below.

${ }^{1} \mathrm{H}$ NMR (300 MHz, DMSO-d $6, \delta$ ): 7.96 (br, 38H, phenyl protons), 7.21 (br, 38H, phenyl protons), 5.00 (br, 19H, NH-CH $\left.2-\mathrm{CH}\left(\mathrm{CH}_{3}\right)-\mathrm{O}-\mathrm{C}=\mathrm{O}\right), 4.72\left(\mathrm{br}, 19 \mathrm{H}, \mathrm{CH}\left(\mathrm{CH}_{3}\right)-\mathrm{OH}\right), 3.51(\mathrm{~m}, 510 \mathrm{H}, \mathrm{PEG}$ protons), 3.24 (s, $3 \mathrm{H}, \mathrm{CH}_{3}-\mathrm{O}-\mathrm{CH}_{2}-\mathrm{CH}_{2}$ ), 2.90 (br, 76H, NH-CH $\mathrm{CH}_{2}-\mathrm{CH}$ ), $1.4-2.0$ (br, $76 \mathrm{H}$, backbone methylene protons), 0.99 (br, $\left.114 \mathrm{H}, \mathrm{NH}-\mathrm{CH}_{2}-\mathrm{CH}\left(\mathrm{CH}_{3}\right)-\mathrm{O}\right), 0.7-0.9$ (br, $114 \mathrm{H}$, backbone methyl protons).

$\underline{\text { P(DMAEMA-co-APM) copolymer }}$ 
AIBN (13 mg, 7.6 $\left.10^{-2} \mathrm{mmol}\right)$, CPDB (55 mg, $\left.0.25 \mathrm{mmol}\right)$, 4-APM (0.5 g, $\left.2.5 \mathrm{mmol}\right)$ and DMAEMA $(0.83 \mathrm{ml}, 4.9 \mathrm{mmol})$ were dissolved in $10 \mathrm{ml}$ of dioxane. The solution was stirred at $70{ }^{\circ} \mathrm{C}$ overnight under reflux in an argon atmosphere. The product was subsequently precipitated in cold heptane. P(DMAEMA-co-APM) was obtained by filtration and dried overnight in vacuo to give orange crystals. Yield: $0.42 \mathrm{~g}(33 \%) .{ }^{1} \mathrm{H} \mathrm{NMR}\left(300 \mathrm{MHz}, \mathrm{CDCl}_{3}, \delta\right): 6.7-7.2$ (br, 16H, phenyl protons), 4.0 - 4.2 (br, $\left.16 \mathrm{H}, \mathrm{O}-\mathrm{CH}_{2}-\mathrm{CH}_{2}-\mathrm{N}\right), 2.5-2.7$ (br, $\left.16 \mathrm{H}, \mathrm{O}-\mathrm{CH}_{2}-\mathrm{CH}_{2}-\mathrm{N}\right), 2.1-2.4$ (br, 48H, N-(CH3)2), $0.8-2.1\left(60 \mathrm{H}\right.$, backbone methyl and methylene protons). SEC: $M_{n} 2200 \mathrm{~g}$ $\mathrm{mol}^{-1}, \oplus 2.7$

\section{Quaternization of P(DMAEMA-co-APM)}

$\mathrm{P}(\mathrm{DMAEMA}-\mathrm{co}-\mathrm{APM})(0.3 \mathrm{~g}, 0.14 \mathrm{mmol})$ and 1-iododecane $(2.5 \mathrm{ml}, 12 \mathrm{mmol})$ were dissolved in $3 \mathrm{ml}$ dioxane. The solution was stirred at $70{ }^{\circ} \mathrm{C}$ overnight under reflux in an argon atmosphere. The product was dissolved in DCM and precipitated in cold heptane. P(qDMAEMA-co-APM) was obtained by filtration and dried overnight in vacuo to a give a light brown powder. Yield: $0.48 \mathrm{~g}$ $(80 \%)$.

\subsection{Characterization of monomer and polymers}

${ }^{1} \mathrm{H}$ NMR spectra were recorded on a Bruker AMX300 spectrometer at $25^{\circ} \mathrm{C}$. Compounds were dissolved in $\mathrm{CDCl}_{3}$, DMSO- $\mathrm{d}_{6}$ or $\mathrm{D}_{2} \mathrm{O}$ at a concentration of $15 \mathrm{mg} \mathrm{ml}^{-1}$. As a standard, residual internal $\mathrm{CHCl}_{3}(\delta 7.26)$, DMSO $(\delta 2.50)$ or $\mathrm{H}_{2} \mathrm{O}(\delta 4.79)$ was used.

The number-average and weight-average molar masses $\left(M_{n}\right.$ and $M_{w}$, respectively) and dispersity $\left(\bigoplus, M_{w} / M_{n}\right)$ of the polymers were determined by size exclusion chromatography (SEC). For the (PEG-XK)2-ABCPA and (PEG-XK)-P(HPMA) polymers, a Viscotek GPCmax VE2100 liquid 
chromatograph equipped with a Viscotek VE3580 refractive index detector operating at $35^{\circ} \mathrm{C}$ was employed. Tetrahydrofuran was used as the eluent and the flow rate was set up at $1.0 \mathrm{ml} \mathrm{min}{ }^{-1}$. Two LT5000L $300 \times 7.8 \mathrm{~mm}$ columns operating at $29^{\circ} \mathrm{C}$ were used. Calibrations were performed with polystyrene standards. For the P(DMAEMA-co-APM) polymer, measurements were performed on a system consisting of a Waters 515 HPLC pump and a Waters 410 refractive index detector operating at $40{ }^{\circ} \mathrm{C}$. Dimethylformamide with $0.1 \% \mathrm{LiBr}$ was used as the eluent and the

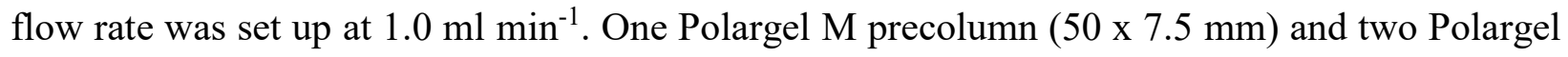
M columns $(300 \times 7.5 \mathrm{~mm})$ operating at $60{ }^{\circ} \mathrm{C}$ were used. Calibrations were performed with poly(methyl methacrylate) standards.

\subsection{Preparation of functionalized PEEK surfaces}

Medical grade PEEK (PEEK-OPTIMA ${ }^{\mathrm{TM}}$, Invibio Ltd, UK) discs of $13 \mathrm{~mm}$ in diameter and 2 $\mathrm{mm}$ in height were used. Anti-fouling polymer ((PEG-XK)-P(HPMA-N $\left.)_{3}\right)$, bactericidal polymer (P(qDMAEMA-co-APM $))$ or a combination of both $(1 / 1 w / w)$ was dissolved in ethanol at a concentration of $5 \mathrm{mg} \mathrm{ml}^{-1}$. After filtration through $0.45 \mathrm{~mm}$ syringe filters, the solution was applied on the surface of PEEK discs using an Infinity airbrush. After evaporation of the ethanol, the PEEK discs were irradiated for 30 s using a Dymax PC-1200 UV curing flood lamp (mercury lamp, $400 \mathrm{~W}$ ). After irradiation the surfaces were washed in ethanol for $10 \mathrm{~min}$ using an ultrasonic bath, followed by drying in vacuo. The surface functionalization procedure was repeated twice.

\subsection{Characterization of functionalized PEEK surfaces}

The functionalized PEEK surfaces were characterized by Fourier Transform Infrared Spectroscopy (FTIR) analyses, X-ray photoelectron spectroscopy (XPS) analyses, and Atomic 
Force Microscopy (AFM) analyses. Static contact angle measurements were also performed. Details of equipment and procedures are provided as supplementary data.

\subsection{In vitro assessment of anti-fouling properties}

Following the surface modification of the complete PEEK surface and prior to biological testing, the discs were cleaned by sonication in 2-propanol (15 min at $400 \mathrm{~W}), 70 v / v \%$ ethanol (10 $\mathrm{min}$ at $400 \mathrm{~W})$ and $\mathrm{dH}_{2} \mathrm{O}(10 \mathrm{~min}$ at $400 \mathrm{~W})$ in a sonication bath (Sonorex Bandelin, Berlin, Germany). The PEEK discs were allowed to dry under sterile laminar flow overnight. PEEK discs grafted with (PEG-XK)-P(HPMA-N 3$)(n=3)$ were incubated using standard culture condition $\left(37^{\circ} \mathrm{C}\right.$ and $5 \% \mathrm{CO}_{2}$ ) for $1 \mathrm{~h}$ in $3 \mathrm{ml}$ of $S$. aureus or E. coli suspension in PBS (calibrated to an $O D_{600}$ of 0.05 , corresponding to approximately $3.0 \times 10^{7}$ colony forming units (CFU) $\mathrm{ml}^{-1}$ ) and kept under mild agitation using a shaker (30 rpm). After $1 \mathrm{~h}$, the discs were removed from the bacterial suspension, washed three times in fresh solutions of PBS, and subsequently sonicated in a sonication bath at $400 \mathrm{~W}$ for $5 \mathrm{~min}$ in $5 \mathrm{ml}$ of PBS to remove adherent bacteria from the PEEK discs. The sonicates were serial diluted in PBS $(1 / 10 v / v)$ and $20 \mu 1(\mathrm{n}=6)$ of each dilution was plated on TSA plates. CFU were counted manually on the agar plates after $18 \mathrm{~h}$ of incubation $\left(37^{\circ} \mathrm{C}\right.$ and $\left.5 \% \mathrm{CO}_{2}\right)$.

\subsection{In vitro assessment of combined anti-fouling and bactericidal properties}

PEEK discs grafted with (PEG-XK)-P(HPMA-N 3 ) and/or P(qDMAEMA-co-APM) were cleaned by sonication in alcohol solutions as described previously. The discs were incubated for 1 $\mathrm{h}$ or for $24 \mathrm{~h}$ in $3 \mathrm{ml}$ of $S$. aureus suspension in PBS $\left(O D_{600}=0.05\right)$. In this experiment, the bacteria suspensions were supplemented with $2 \% v / v$ human serum and $2 \% v / v$ TSB to simulate semiphysiological conditions. After $1 \mathrm{~h}$ or $24 \mathrm{~h}$ incubation under shaking (30 rpm), the discs were 
washed 3 times by transferring them to fresh solutions of PBS. The remaining adherent bacteria were sonicated, plated and counted as described previously. For every investigated PEEK disc, a sonicate bacterial dispersion was stained with a LIVE/DEAD ${ }^{\circledR}$ BacLight ${ }^{\mathrm{TM}}$ Bacterial Viability Kit L13152 according to manufacturer's instructions and subsequently imaged by a ZEISS LSM 800 confocal microscope (Carl Zeiss, Feldbach, Switzerland).

\subsection{Stability of coating during alcohol cleaning versus steam sterilization}

Alcohol cleaning of PEEK discs was done in three steps as described previously. Steam sterilization of PEEK discs occurred at standard conditions of $121{ }^{\circ} \mathrm{C}$ for $20 \mathrm{~min}$. PEEK discs (n =3) cleaned/sterilized by one of both methods were exposed to $S$. aureus suspension in PBS as described earlier.

\subsection{Evaluation of cytotoxicity via extraction method (ISO 10993-5)}

A detailed procedure concerning the evaluation of the cytotoxicity of the coatings is provided in the supplementary data.

\section{Results and discussion}

\subsection{Synthesis and characterization of anti-fouling and bactericidal polymers}

PEEK exhibits unprecedented advantages compared to commonly used materials in implantology, with one of the most attractive ones being its processability by additive manufacturing [4]. Nevertheless, as with any other implant material, PEEK is not free of bacterial contamination $[6,29,30]$. We covalently grafted a combination of anti-fouling and bactericidal 
polymers on the PEEK surface as a potentially synergistic, powerful combination to prevent PEEK implant infection (Figure 1).

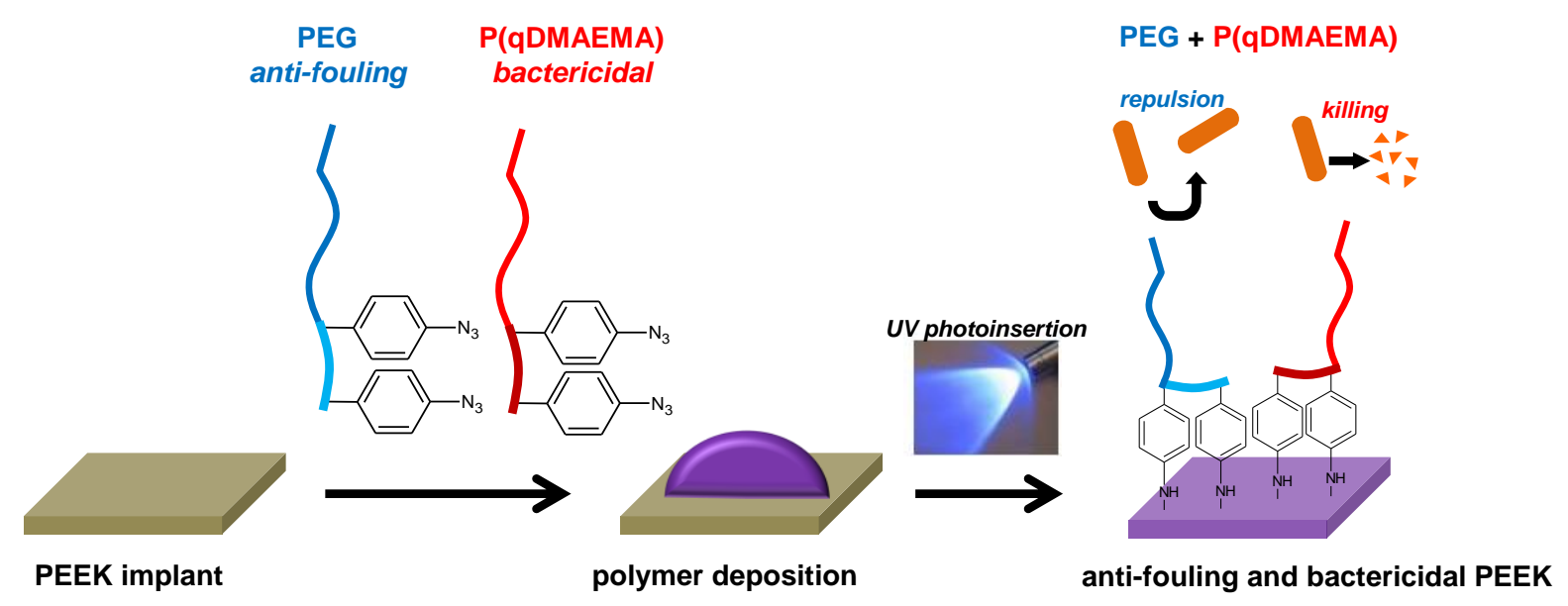

Figure 1. Schematic illustration of the grafting process of synergistically operating anti-fouling PEG and bactericidal P(qDMAEMA) onto PEEK via aryl-azide UV photoinsertion.

As anti-fouling polymer we selected PEG, as its immobilization onto a biomaterial surface has been shown to increase hydrophilicity and decrease protein adsorption, thereby preventing cells to attach [31]. The PEG block was extended with a second polymer block, poly(2-hydroxypropyl methacrylamide) (P(HPMA)), to allow for subsequent P(HPMA) functionalization with aryl-azide groups (Figure 2), which facilitate grafting onto the PEEK surface via UV photoinsertion. We chose P(HPMA) as the second polymer block because of its hydrophilicity, biocompatibility, nonimmunogenicity and the possibility for straightforward chemical modification via derivatization of its pendant hydroxyl groups [32]. Aryl-azide functionalized PEG-P(HPMA) block copolymers with a PEG molecular weight of 2, 5 or $12 \mathrm{~kg} \mathrm{~mol}^{-1}$ were prepared to allow investigation of the PEG length on the anti-fouling and bactericidal behavior. The synthesis of aryl-azide functionalized PEG-P(HPMA) with a PEG molecular weight of $5 \mathrm{~kg} \mathrm{~mol}^{-1}$ ((PEG-5K)-P(HPMA- 
$\left.\mathrm{N}_{3}\right)$ ), which is representative for its analogs (PEG-2K)-P(HPMA-N 3 ) and (PEG-12K)-P(HPMA$\mathrm{N}_{3}$ ), is discussed below.

In the first step, the macro-initiator (PEG-5K) $)_{2}$ ABCPA was prepared using a previously reported procedure [28]. Its structure was confirmed by ${ }^{1} \mathrm{H}$ NMR (Figure S1). Similarly to our previous finding, the SEC trace of (PEG-5K) 2 -ABCPA (Figure S2) reveals the presence of a small amount of PEG-5K homopolymer that originates from the macroinitiator synthesis as discussed elsewhere [32]. Other groups showed that the separation of the $(\mathrm{PEG}-5 \mathrm{~K})_{2}-\mathrm{ABCPA}\left(10 \mathrm{~kg} \mathrm{~mol}^{-1}\right)$ and PEG-5K homopolymer via common separation techniques, was impractical, expensive and not efficient due to their close molecular weights [33]. For this reason, the macro-initiator (PEG$5 \mathrm{~K})_{2}$-ABCPA was subsequently used without further purification for the preparation of (PEG-5K)P(HPMA) block copolymer via free radical polymerization of HPMA to allow for the introduction of multiple aryl-azide groups in a next step via modification of the hydroxyl side groups in the P(HPMA) block (Figure 2). This absence of purification is not detrimental for the final goal as will be highlighted in the next parts. 

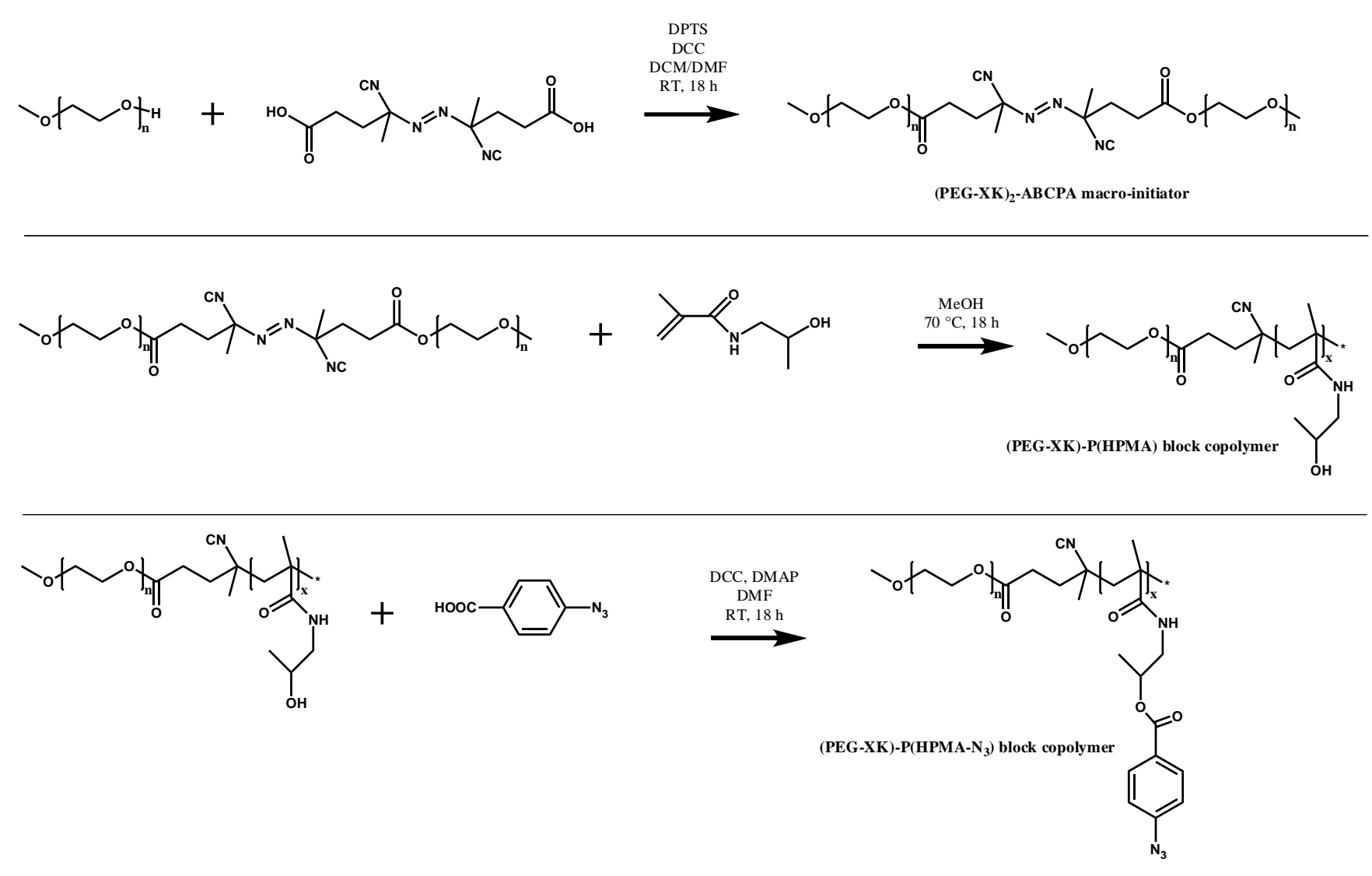

Figure 2. Synthesis scheme for the preparation of (PEG-XK)-P(HPMA-N $\left.{ }_{3}\right)$.

An average degree of polymerization (DP) of 40 was calculated by ${ }^{1} \mathrm{H}$ NMR analysis for the P(HPMA) block (copolymer $M_{n} 10.7 \mathrm{~kg} \mathrm{~mol}^{-1}$ ). This result was obtained by comparison between the integral of the peak accounting for the HPMA pendant methine protons and the integral of the peak accounting for PEG protons (Figure S3). SEC analysis of (PEG-5K)-P(HPMA) (Figure S2) shows the presence of PEG-5K that was already present in the starting (PEG-5K) $)_{2}-\mathrm{ABCPA}$, but that could also be due to chain transfer and primary radical recombination. This chain termination could be limited by using atom transfer radical polymerization (ATRP) [34] and reversible addition-fragmentation chain transfer (RAFT) polymerization [35]. This improvement was not carried out in the frame of this work as PEG-5K is not functionalized with aryl-azide groups in the 
next step, and therefore is not grafted on the PEEK surface. A $D$ of 1.34 was found for (PEG-5K)P(HPMA), close to what was reported elsewhere using a similar procedure [32].

In the final step of the synthetic procedure, aryl-azide groups were introduced via an esterification reaction between 4-azidobenzoic acid and the hydroxyl side groups in the P(HPMA) block. In the ${ }^{1} \mathrm{H}$ NMR spectrum of the resulting (PEG-5K)-P(HPMA-N 3 ) signals at 7.96 and 7.21 ppm are visible (Figure 3A), corresponding to the phenyl protons of the aryl-azide groups. By comparing the ${ }^{1} \mathrm{H}$ NMR integrals of the aromatic protons and methine protons, it was calculated that $50 \%$ of the HPMA units was functionalized with aryl-azide groups. Although no quantitative functionalization was achieved, possibly due to the relatively low amount of 4-azidobenzoic acid in the reaction mixture (equimolar relative to hydroxyl groups) in combination with steric hindrance effects, each (PEG-5K)-P(HPMA-N ${ }_{3}$ ) polymer contains approximately 15-20 aryl-azide groups for grafting onto PEEK surfaces via UV photoinsertion. The non-quantitative functionalization of (PEG-5K)-P(HPMA-N 3 ) could be beneficial in view of its grafting to the PEEK surface as a larger distance and hence higher flexibility between the aryl-azide moieties likely promotes multiple attachments to the surface [23]. 


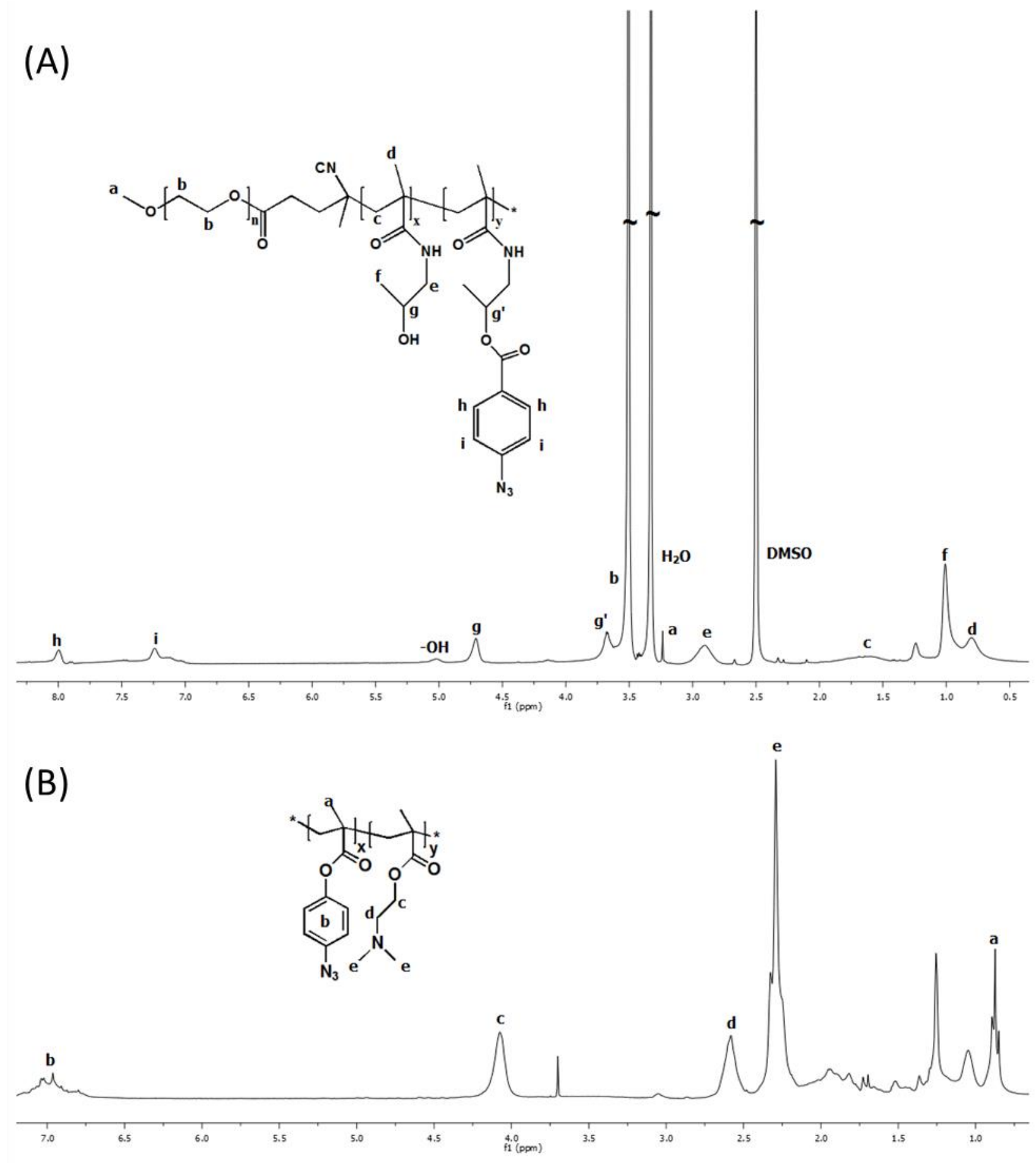

Figure 3. Typical ${ }^{1} \mathrm{H}$ NMR spectra of photoactivable copolymers with (A) ${ }^{1} \mathrm{H}$ NMR spectrum of (PEG-5K)-P(HPMA-N 3 ) (Solvent: DMSO-d 6 ); (B) ${ }^{1} \mathrm{H}$ NMR spectrum of P(DMAEMA-co-APM). The signal at $3.70 \mathrm{ppm}$ corresponds to trace amounts of dioxane. Unassigned peaks correspond to backbone protons (Solvent: $\left.\mathrm{CDCl}_{3}\right)$. 
Following the same three-step synthetic procedure (Figure 2), (PEG-2K)-P(HPMA-N $)_{3}$ and (PEG-12K)-P(HPMA-N 3 ) block copolymers were prepared, having a P(HPMA) DP of 40 and a degree of functionalization of the HPMA units with aryl-azide groups of approximately $75 \%$.

We selected poly(2-(dimethylamino)ethyl methacrylate) P(DMAEMA) [36] as a bactericidal polymer based on our previous study [37] which showed that short $\left(<10 \mathrm{~kg} \mathrm{~mol}^{-1}\right)$ PDMAEMA provides a high antibacterial activity with limited toxic effects on cells. In order to obtain bactericidal polymers which can be grafted onto PEEK surfaces via UV photoinsertion, we synthesized PDMAEMA based polymers with tertiary amines as well as aryl-azide groups, followed by quaternization of the tertiary amines (Figure 4).
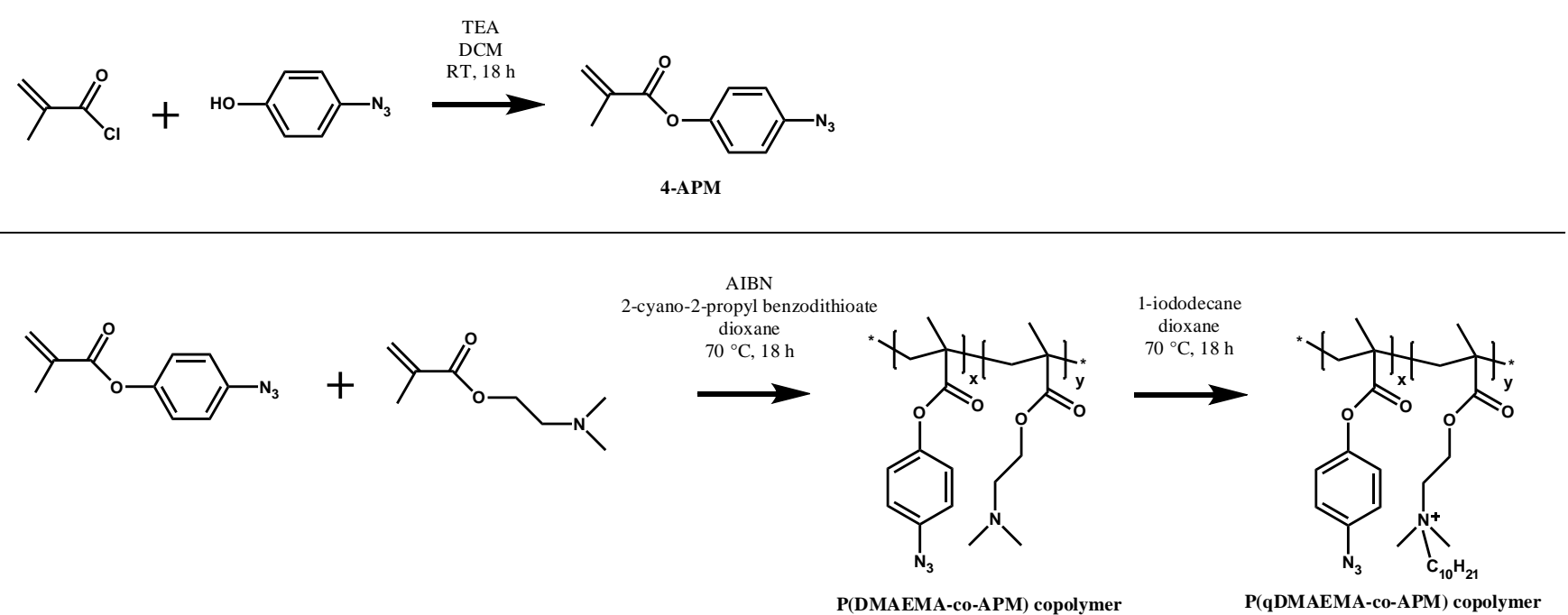

Figure 4. Synthesis scheme for the preparation of P(qDMAEMA-co-APM).

The monomer 4-azidophenyl methacrylate (4-APM) was synthesized by reaction of 4azidophenol and methacryloyl chloride [27]. After purification, the product was obtained in $60 \%$ 
yield and its structure was confirmed by ${ }^{1} \mathrm{H}$ NMR spectroscopy (Figure S4). P(DMAEMA-coAPM) copolymer was synthesized by RAFT copolymerization of 4-APM and DMAEMA. Comparison of the ${ }^{1} \mathrm{H}$ NMR spectra of the reaction mixture before and after $18 \mathrm{~h}$ of polymerization indicated full conversion of the monomers (data not shown). After purification the polymer was obtained in $32 \%$ yield. By comparing the ${ }^{1} \mathrm{H}$ NMR integrals of the aromatic signals in the 4-APM units and the pendant methylene protons in the DMAEMA units (Figure 3B), the DMAEMA/4APM ratio was calculated to be $2 / 1$, in accordance with the feed ratio. SEC analysis showed a $M_{n}$ of approximately $2200 \mathrm{~g} \mathrm{~mol}^{-1}$, which is significantly lower than the targeted $M_{n}\left(4500 \mathrm{~g} \mathrm{~mol}^{-1}\right)$. Since full monomer conversion was achieved, yet the targeted polymer $M_{n}$ was not reached, it is thought that significant oligomerization took place resulting from preliminary primary radical combination and chain transfer. Furthermore, azido groups can undergo cycloaddition to carbon double bonds at higher temperature. These low-molecular weight products are likely removed during purification, which may also explain the relatively low polymer yield (32\%). The limited control over the polymerization results in a relatively high $Ð(2.7)$ as determined by SEC (Figure S5). Li et al. reported good control $(\nexists<1.3)$ over the RAFT homopolymerization of 4-APM and its copolymerization with acrylate monomers at room temperature using the redox initiator system benzoyl peroxide/ $N, N$-dimethylaniline [27]. However, in our experience, RAFT copolymerization of 4-APM with DMAEMA at room temperature resulted in very low conversions of less than 10 $\%$. Copolymerization at $70{ }^{\circ} \mathrm{C}$ led to full monomer conversion, but these conditions may also have caused side reactions and a limited control over the copolymerization due to the sensitivity of the azido group to high temperatures. Our current efforts focus on improving the control over the copolymerization of 4-APM and DMAEMA as well as elucidating the arrangement of 4-APM and DMAEMA units along the copolymer chain. 
After the synthesis of P(DMAEMA-co-APM), we applied a straightforward quaternization reaction involving 1-iododecane (Figure 4). FTIR confirmed quaternization of the P(DMAEMAco-APM) copolymer as signals corresponding to the $\mathrm{C}-\mathrm{H}$ stretching vibrations of 1-iododecane appeared in the spectrum of $\mathrm{P}(\mathrm{qDMAEMA}-\mathrm{co}-\mathrm{APM})$ (Figure S6). Comparison of the ${ }^{1} \mathrm{H}$ NMR integrals of the aromatic signals in the 4-APM units and the 1-iododecane methylene protons indicated full quaternization of the DMAEMA units (data not shown).

\subsection{Surface functionalization of PEEK with anti-fouling and bactericidal polymers via photoinsertion}

The PEEK surfaces were analyzed for hydrophilicity by static water contact angle measurements (Figure 5). The results demonstrate successful covalent attachment of (PEG-XK)-P(HPMA-N ${ }_{3}$ at the surface of the PEEK discs, as UV irradiated, PEG-sprayed surfaces exhibit a lower contact angle, i.e. a higher hydrophilicity, compared to UV irradiated native PEEK. In line with expectations and previous literature $[38,39]$, the contact angle decreases with increasing PEG chain length. Functionalization of the PEEK surface with P(DMAEMA-co-APM) also results in a lower contact angle $\left(68^{\circ}\right)$. This value is in good agreement with the water contact angle $\left(66^{\circ}\right)$ on a silicon surface functionalized with a copolymer based on DMAEMA and n-butyl methacrylate in a 2:1 ratio [40]. After quaternization of the DMAEMA groups with 1-iododecane the contact angle increases to $93^{\circ}$, despite the presence of hydrophilic quaternary ammonium groups. Previously it was shown that the contact angle depends on the balance between the hydrophilic charged groups and the hydrophobic parts of macromolecules present on a surface [41]. It is hypothesized that in the present study the hydrophilic effect of the charged ammonium groups is outweighed by the hydrophobicity of the long alkyl chains. 


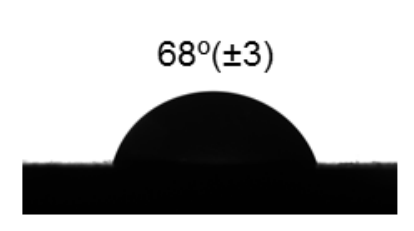

(PEG-2K)-P(HPMA-N $\left.{ }_{3}\right)$

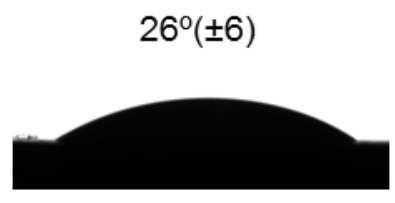

(PEG-5K)-P(HPMA-N ${ }_{3}$ )

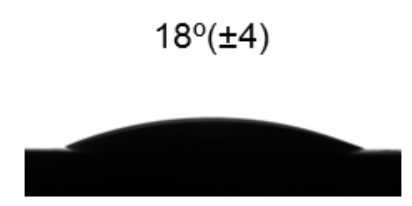

(PEG-12K)-P(HPMA-N $\left.{ }_{3}\right)$

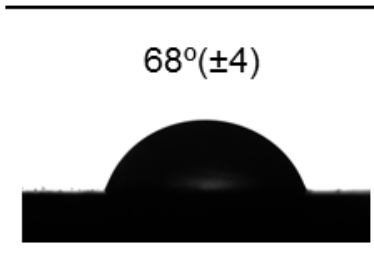

P(DMAEMA-CO-APM)

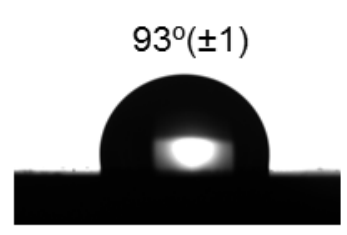

P(qDMAEMA-co-APM)

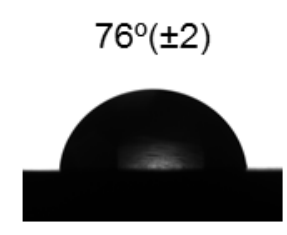

Native PEEK

Figure 5. Contact angles for PEEK surfaces functionalized with various polymers. Contact angles $(n=3)$ are expressed as mean \pm standard deviation.

Upon UV irradiation of (PEG-5K)-P(HPMA-N 3$)$ and P(qDMAEMA-co-APM) copolymer on PEEK, the FTIR signals corresponding to the $\mathrm{N}_{3}$ stretching vibrations disappear, which confirms the successful photoinsertion of the aryl-azide groups (Figures S7 and S8). The emergence of a nitrogen peak in X-ray photoelectron spectra (XPS) of PEEK functionalized with (PEG-5K)$\mathrm{P}\left(\mathrm{HPMA}_{3}\right)$ or $\mathrm{P}(\mathrm{qDMAEMA}-\mathrm{No}-\mathrm{APM})$ (Figure $\left.6 \mathrm{~A}\right)$ further corroborates the successful grafting of the anti-fouling and bactericidal polymers. Atomic force microspcopy (AFM) measurements showed that the surface roughness of PEEK increases from $34 \mathrm{~nm}$ to $220 \mathrm{~nm}$ upon functionalization with (PEG-5K)-P(HPMA-N $)$ (Figure 6B). Overall, the contact angle, FTIR, XPS and AFM experiments clearly demonstrate that PEEK was successfully modified with covalently immobilized anti-fouling (PEG-XK)-P(HPMA-N 3 ) and bactericidal P(qDMAEMA-coAPM) polymers. 


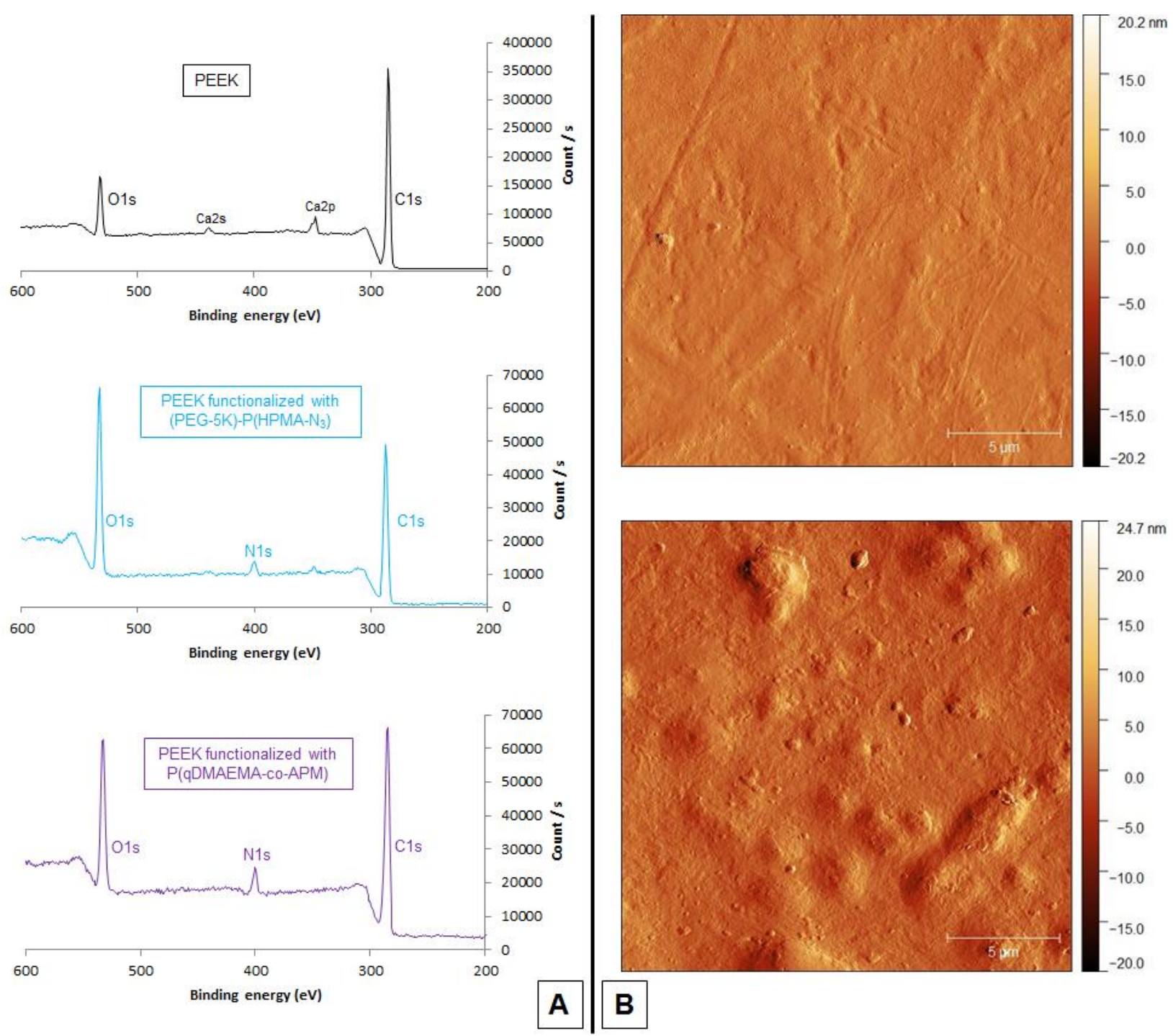

Figure 6. (A) XPS spectra of PEEK, PEEK functionalized with (PEG-5K)-P(HPMA-N 3 ) and PEEK functionalized with P(qDMAEMA-co-APM). (B) AFM images of unfunctionalized PEEK (top, surface roughness $34 \mathrm{~nm}$ ) and PEEK functionalized with (PEG-5K)-P(HPMA-N 3 ) (bottom, surface roughness $220 \mathrm{~nm}$ ).

\subsection{In vitro assessment of anti-fouling and bactericidal properties of functionalized PEEK surfaces}

The anti-fouling test against Gram-positive $S$. aureus, presented in Figure 7A, revealed that all (PEG-XK)-P(HPMA-N 3 coatings could significantly reduce bacterial adhesion after $1 \mathrm{~h}$ of 
incubation in PBS, with stronger effects observed for longer PEG chain lengths. Against Gramnegative E. coli, the effects were less apparent, with the shortest PEG coating lacking significant differences in CFU (colony forming units) attachment compared with native PEEK (Figure 7B). For both bacterial strains, increasing PEG chain length negatively affects the ability of bacteria to adhere on the surface of (PEG-XK-P(HPMA-N 3 ) functionalized PEEK. Thus, the best anti-fouling effect was observed with (PEG-12K)-P(HPMA-N 3 ), which caused a CFU adhesion reduction of $92 \%$ and $60 \%$ for S. aureus and E. coli respectively (Figure 7A and 7B).

Repeating the same experiment with $S$. aureus in medium containing human serum showed different behavior after $1 \mathrm{~h}$ (Figure 7C). Indeed, due to the protein presence in the suspension medium, the initial anti-fouling effect observed in Figures 7A and 7B was eliminated. Longer incubation time (24 h) was necessary to observe the anti-fouling effect of (PEG-XK)-P(HPMA$\mathrm{N}_{3}$ ) coatings and its previously observed dependence on the chain length, albeit not as pronounced as reported when only PBS was employed as incubating medium. On PEEK surfaces only modified with P(qDMAEMA-co-APM), no diminution of CFU was noted compared to unmodified PEEK over the course of the experiment. For combined coatings, the PEG chain length influences the degree in which the shorter $\mathrm{P}(\mathrm{qDMAEMA}-\mathrm{co}-\mathrm{APM})$ polymers are exposed to the bacterial suspension and thus their potential bactericidal effect. 
A.

S. aureus

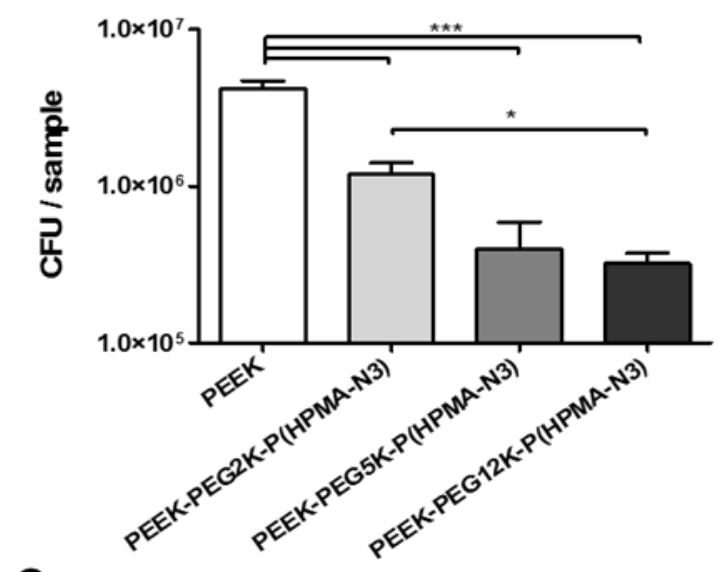

C.

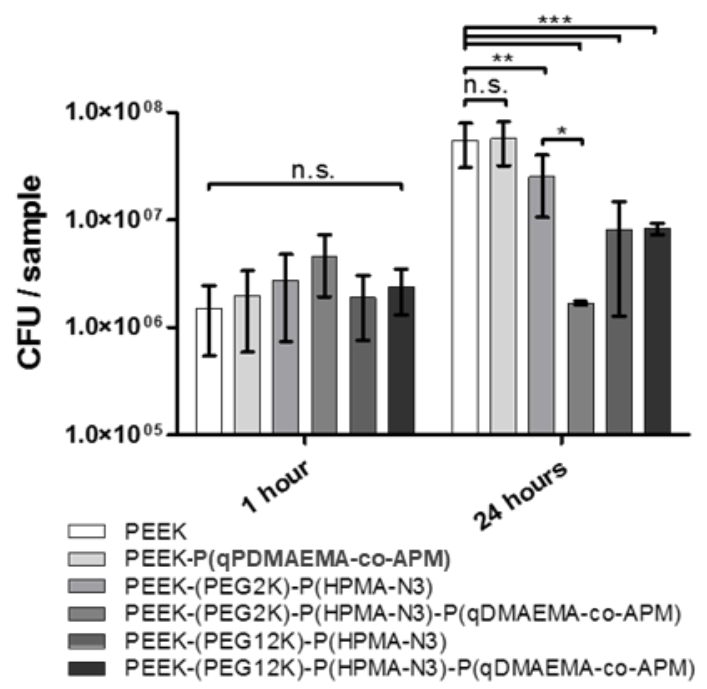

B.

E. coli

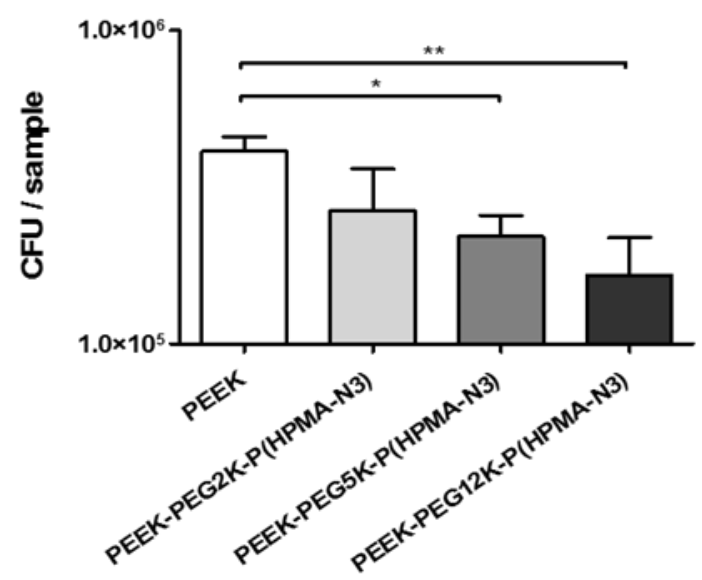

D.
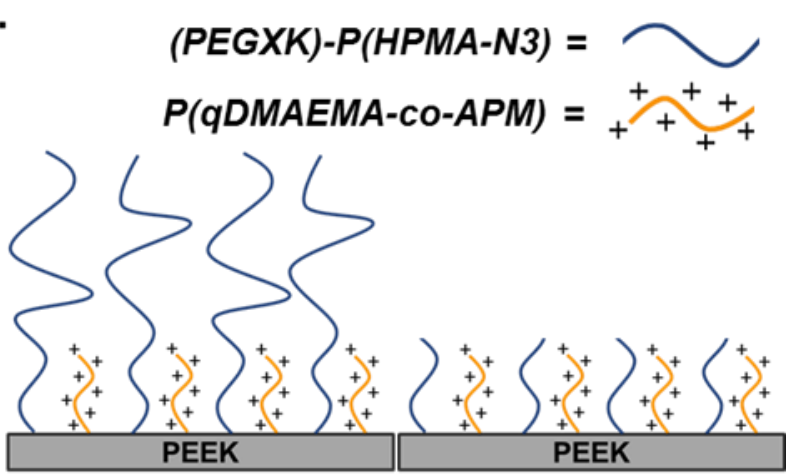

PEG $M_{W}=12.000 \mathrm{~g} / \mathrm{mol} \quad P E G M_{W}=2.000 \mathrm{~g} / \mathrm{mol}$

Figure 7. (A) Assessment of anti-fouling properties of functionalized PEEK surfaces against $S$. aureus. (B) Assessment of anti-fouling properties of the functionalized PEEK surfaces against $E$. Coli. (C) Combined anti-fouling and/or bactericidal effects of (PEG-XK)-P(HPMA-N ${ }_{3}$ ), P(qDMAEMA-co-APM) and combined coatings against $S$. aureus over $24 \mathrm{~h}$ in semi-physiological conditions. (D) Schematic representation of (PEG-XK)-P(HPMA-N $\left.{ }_{3}\right)$ and P(qDMAEMA-coAPM) polymers on PEEK surfaces. All data was subjected to 2-way ANOVA with Bonferroni post-test $(*=\mathrm{p}<0.05, * *=\mathrm{p}<0.01$ and $* * *=\mathrm{p}<0.001)$. 
The bactericidal effect of the P(qDMAEMA-co-APM) chains becomes clearly detectable only when associated with (PEG-2K)-P(HPMA-N 3 ) and after $24 \mathrm{~h}$ of incubation as evidenced by a live/dead staining (Figure S9). A synergistic effect in terms of reduction of S. aureus adhesion can thus be seen only when $\mathrm{P}(\mathrm{qDMAEMA}-\mathrm{co}-\mathrm{APM})$ is combined with (PEG-2K)-P(HPMA-N 3$)$, and not with the longer (PEG-12K)-P(HPMA-N $)$ (which exhibited the best anti-fouling property as presented Figure 7A and 7B). This is evidenced by the similar values of adherent CFU for the (PEG-12K)-P(HPMA-N 3 ) and (PEG-12K)-P(HPMA-N 3$)+$ P(qDMAEMA-co-APM) groups. When the PEG chains have an approximately equal size as P(qDMAEMA-co-APM) chains (as is the case for (PEG-2K)-P(HPMA-N 3$)$ ), close to a 2-log (99 \%) reduction could be observed compared to the PEEK control group. Combination of P(qDMAEMA-co-APM) chains with much longer PEG chains resulted in a loss of bactericidal capacity. This phenomenon can be explained by steric hindrance and masking of the P(qDMAEMA-co-APM) chains, which prevents interaction with the bacterial wall due to the larger size of the PEG chains (Figure 7D).

Ishihari et al. reported $91 \%$ reduction in $S$. mutans adherence on PEEK after grafting poly(2methacryloyloxyethyl phosphorylcholine) (PMPC) onto the surface of PEEK via aryl-azide UV photoinsertion of PMPC [12]. This value is comparable with the anti-fouling effect we observed for the (PEG-12K)-P(HPMA-N 3 ) functionalized PEEK (92\% reduction for $S$. aureus). The significantly higher reduction in bacterial adhesion (99\%, Figure 7C) when PEG is combined with $\mathrm{P}(\mathrm{qDMAEMA-co-APM})$ confirms our hypothesis that grafting a combination of anti-fouling polymer and bactericidal polymer is a relevant synergistic approach to prevent bacterial adhesion on PEEK implants.

To facilitate the clinical translation of any medical device endowed with anti-infectious properties, it is important to assess their stability through sterilization. The chemical stability of 
the grafted polymers on the PEEK surface was demonstrated by comparing $S$. aureus adhesion on alcohol cleaned discs versus steam sterilized discs (Figure S10). Results between the cleaning and sterilization methods are comparable in terms of CFU reduction of adhesion, with no significant $(\alpha=0.05)$ differences between the two methods. These results confirm that both (PEG-XK)$\mathrm{P}\left(\mathrm{HPMA}-\mathrm{N}_{3}\right)$ and $\mathrm{P}(\mathrm{qDMAEMA}-\mathrm{co}-\mathrm{APM})$ coatings are compatible with steam sterilization.

\subsection{In vitro cytotoxicity of functionalized PEEK surfaces}

The extraction method was used to assess the cytotoxicity of the functionalized PEEK surfaces. Figure 8 shows the viability of fibroblast cells treated with undiluted extracts of PEEK samples and various reference materials relative to the untreated control (extraction vehicle), as determined with the CellTiter-Glo luminescence assay. According to the ISO 10993-5 guidelines, a reduction in cell viability of more than $30 \%$ is considered as a cytotoxic effect. Following expectations, 0.25 $\%$ zinc dibutyldithiocarbamate polyurethane (ZDBC PU) film as well as $60 \mathrm{mM}$ phenol solution (positive controls) greatly reduce the cell viability. In contrast, fibroblast viability in contact with extracts from the functionalized PEEK surfaces is more than $70 \%$, with values comparable to the toxicity of polyethylene film (negative control) and unfunctionalized PEEK. The cytotoxicity was further evaluated using the lactate dehydrogenase (LDH) activity assay. Figure S11 shows the

amount of LDH, a cytosolic enzyme which is released upon cell membrane damage, in the cell culture medium after $24 \mathrm{~h}$. The undiluted extracts of the PEEK samples show a very low toxicity towards fibroblasts after $24 \mathrm{~h}$, comparable to the toxicity of the polyethylene extracts (negative control) and the extraction vehicle, corroborating the cytotoxicity results obtained with the CellTiter-Glo luminescence assay. As expected, treatment with diluted extracts of the PEEK samples resulted in similar low cytotoxicity values (data not shown). These in vitro experiments 
demonstrate that despite clear anti-fouling and bactericidal effects for the PEEK surfaces (Figure 7), the surface functionalization does not induce cytotoxicity for the surrounding medium.

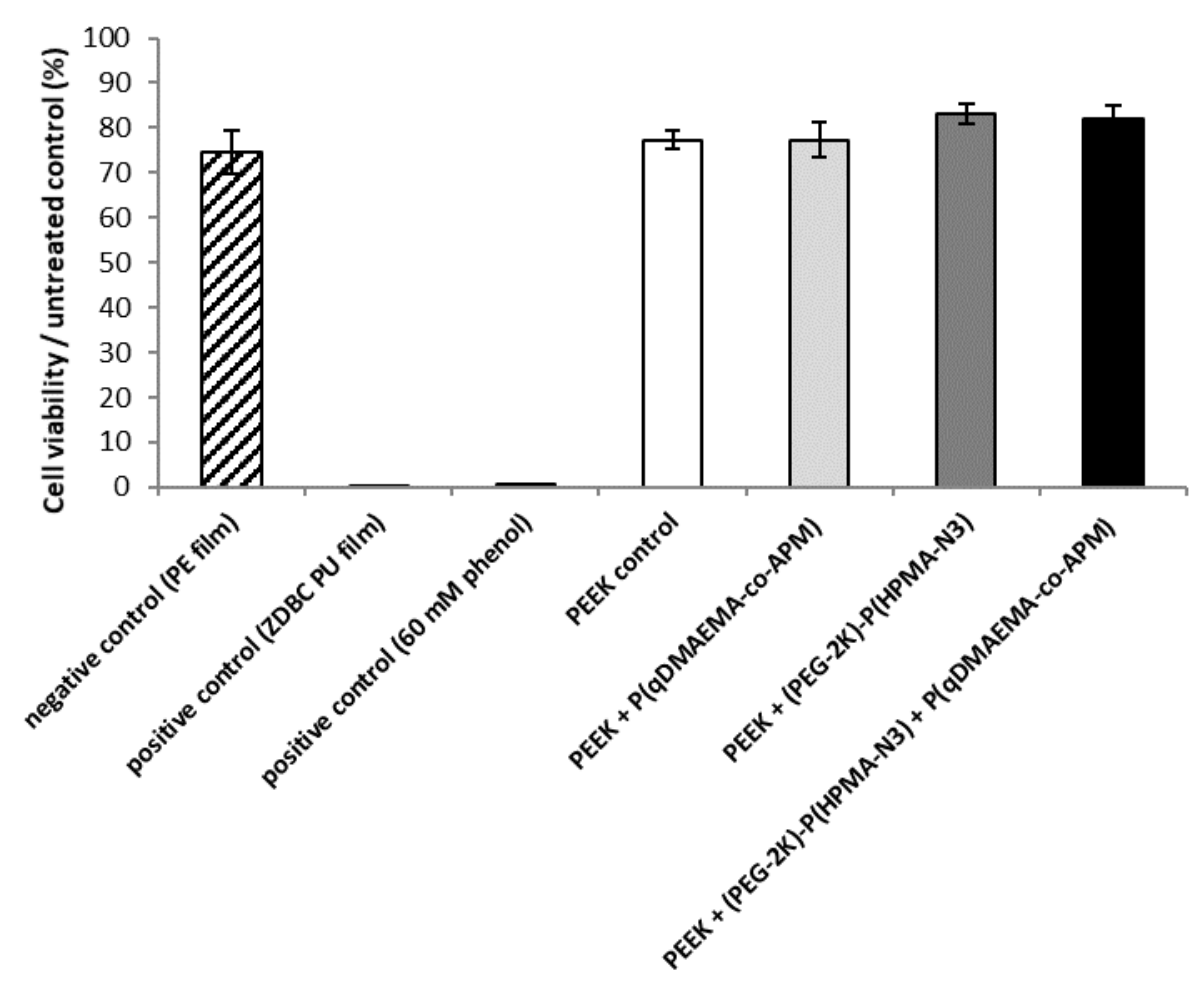

Figure 8. Viability of fibroblasts grown in contact with extracts for $24 \mathrm{~h}$. Data $(n=3)$ are expressed as mean \pm standard deviation. The viability of cells without any treatment (growth medium only) was taken as $100 \%$. According to the ISO 10993-5 guidelines, a reduction in cell viability of more than $30 \%$ is considered as a cytotoxic effect.

Perspective of this work will be to validate the antibacterial protection offered by this synergistic combination of anti-fouling and bactericidal polymers under in vivo conditions. In addition, as implants made of PEEK can easily be processed using additive manufacturing based on patient radiographic scans [4], it would be of interest to validate the developed work-flow on preformed 
patient-specific implants made of PEEK. In this regard, the ability to autoclave the functionalized PEEK samples is highly important for future in vivo assessments and possible clinical application.

\section{Conclusion}

We developed a new method to decrease PEEK implant infection by grafting both anti-fouling and bactericidal polymers onto the surface of PEEK via aryl-azide UV photoinsertion. (PEG-XK)-

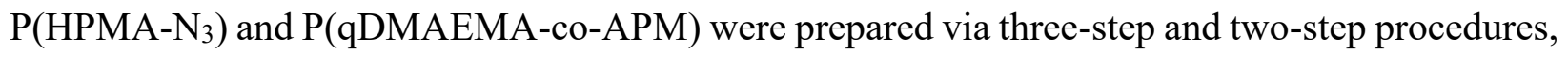
respectively, and their structure was confirmed via ${ }^{1} \mathrm{H}$ NMR. Spray coating of polymer solutions onto PEEK and subsequent UV irradiation yielded functionalized PEEK surfaces. The photoinserted polymers on the PEEK surface significantly improved the in vitro anti-fouling and bactericidal properties. A synergistic effect between (PEG-XK)-P(HPMA-N $)_{3}$ ) and P(qDMAEMAco-APM) could only be observed when both polymers were of approximately equal chain length. The study also revealed that the presence of proteins in the bacteria-containing medium is an important factor to consider in the evaluation of anti-bacterial surfaces. In vitro cytotoxicity experiments on fibroblasts validated the biocompatibility of the biomaterial as no leachable toxic compounds were released from the modified PEEK samples. These functionalized PEEK surfaces show significant promise in diminishing the susceptibility of native PEEK to bacterial attachment.

\section{Supporting Information}

Detailed synthetic procedures, detailed characterization procedures of PEEK surfaces, evaluation of cytotoxicity via extraction method, ${ }^{1} \mathrm{H}$ NMR spectra of (PEG-5K)2-ABCPA (Figure S1), (PEG5K)-P(HPMA) (Figure S3) and 4-APM (Figure S4); SEC traces of PEG-5K, (PEG-5K)2-ABCPA, (PEG-5K)-P(HPMA) (Figure S2) and P(DMAEMA-co-APM) (Figure S5); FTIR spectra of 
$\mathrm{P}(\mathrm{qDMAEMA-co-APM)}$ (Figure S6) as well as functionalized PEEK surfaces (Figure S7 and Figure S8); Live/Dead staining of $S$. aureus cultured on the PEEK discs (Figure S9); direct assessment of cleaning and sterilization compatibility of the grafted polymers on the PEEK surface (Figure S10); contact LDH cytotoxicity assay (Figure S11).

\section{Acknowledgements}

We would like to thank Valérie Flaud (Institut Charles Gerhardt, Montpellier) and Michel Ramonda (Centrale de Technologie en Micro et nanoélectronique, Montpellier) for help with the XPS and AFM measurements, respectively.

\section{Funding Sources}

The authors would like to acknowledge the funding AO CMF-17-02N (PEEK-CAM).

\section{Author Contributions}

The manuscript was written through contributions of all authors. All authors have given approval to the final version of the manuscript.

\section{Declaration of Competing Interests}

The authors have no competing financial interest to declare.

\section{References}

[1] D.F. Williams, A. McNamara, R.M. Turner, Journal of Materials Science Letters, 6 (1987) 188-190.

[2] S.M. Kurtz, J.N. Devine, Biomaterials, 28 (2007) 4845-4869.

[3] S.M. Kurtz, PEEK Biomaterials Handbook.1st edition.Waltham, MA: William Andrew, (2012). 
[4] E. Alonso-Rodriguez, J.L. Cebrián, M.J. Nieto, J.L. Del Castillo, J. Hernández-Godoy, M. Burgueño, Journal of Cranio-Maxillofacial Surgery, 43 (2015) 1232-1238.

[5] M.M. Hanasono, N. Goel, F. DeMonte, Annals of Plastic Surgery, 62 (2009) 653-655.

[6] G. Rosenthal, I. Ng, S. Moscovici, K.K. Lee, T. Lay, C. Martin, G.T. Manley, Neurosurgery, 75 (2014) 523-529.

[7] O. Nemoto, A. Kitada, S. Naitou, A. Tachibana, Y. Ito, A. Fujikawa, European Journal of Orthopaedic Surgery \& Traumatology, 25 (2015) 127-134.

[8] M. Cotic, S. Vogt, S. Hinterwimmer, M.J. Feucht, J. Slotta-Huspenina, T. Schuster, A.B. Imhoff, Knee Surgery, Sports Traumatology, Arthroscopy, 23 (2015) 2032-2040.

[9] E.L. Steinberg, E. Rath, A. Shlaifer, O. Chechik, E. Maman, M. Salai, 2013, pp. 221-228.

[10] E. Alexakou, M. Damanaki, P. Zoidis, E. Bakiri, N. Mouzis, G. Smidt, S. Kourtis, The European journal of prosthodontics and restorative dentistry, 27 (2019) 113-121.

[11] M. Kyomoto, T. Moro, Y. Takatori, H. Kawaguchi, K. Nakamura, K. Ishihara, Biomaterials, 31 (2010) 1017-1024.

[12] K. Ishihara, K. Fukazawa, Y. Inoue, J. Koyama, Y. Mori, T. Kinoshita, K. Hiranuma, N. Yasuda, Journal of Applied Polymer Science, 135 (2018) 46512.

[13] T. Tateishi, M. Kyomoto, S. Kakinoki, T. Yamaoka, K. Ishihara, Journal of Biomedical Materials Research Part A, 102 (2014) 1342-1349.

[14] P. Amdjadi, H. Nojehdehian, F. Najafi, A. Ghasemi, M. Seifi, E. Dashtimoghadam, F. Fahimipour, L. Tayebi, Journal of Biomaterials Applications, 32 (2017) 3-11.

[15] A. Yousaf, A. Farrukh, Z. Oluz, E. Tuncel, H. Duran, S.Y. Doğan, T. Tekinay, H.u. Rehman, B. Yameen, 2014, pp. 70-75.

[16] H. Kakinuma, K. Ishii, H. Ishihama, M. Honda, Y. Toyama, M. Matsumoto, M. Aizawa, Journal of Biomedical Materials Research Part A, 103 (2015) 57-64.

[17] D.J. Jaekel, Development and fabrication of silver composite PEEK to prevent microbial attachment and periprosthetic infection, 2012.

[18] S. Silver, FEMS microbiology reviews, 27 (2003) 341-353.

[19] C.E. Albers, W. Hofstetter, K.A. Siebenrock, R. Landmann, F.M. Klenke, Nanotoxicology, 7 (2013) 30-36.

[20] K. Mijnendonckx, N. Leys, J. Mahillon, S. Silver, R. Van Houdt, Biometals, 26 (2013) 609621.

[21] E.T.J. Rochford, A.H.C. Poulsson, J. Salavarrieta Varela, P. Lezuo, R.G. Richards, T.F. Moriarty, 2014, pp. 213-222.

[22] A.M. Klibanov, Journal of Materials Chemistry, 17 (2007) 2479-2482.

[23] A. Schulz, A. Stocco, A. Bethry, J.P. Lavigne, J. Coudane, B. Nottelet, Advanced Functional Materials, 28 (2018) 1800976.

[24] I. Dunkin, A. El Ayeb, S. Gallivan, M. Lynch, Journal of the Chemical Society, Perkin Transactions 2, (1997) 1419-1428.

[25] K. Ulbrich, V. Šubr, J. Strohalm, D. Plocova, M. Jelınková, B. Říhová, Journal of Controlled Release, 64 (2000) 63-79.

[26] H. Wu, Y. Yang, Y.C. Cao, Journal of the American Chemical Society, 128 (2006) 1652216523.

[27] G. Li, H. Zheng, R. Bai, Macromolecular rapid communications, 30 (2009) 442-447.

[28] D. Neradovic, C.F. Van Nostrum, W.E. Hennink, Macromolecules, 34 (2001) 7589-7591.

[29] R.H. Khonsari, P. Berthier, T. Rouillon, J.-P. Perrin, P. Corre, 2014, pp. 477-482. 
[30] S. Järvinen, J. Suojanen, E. Kormi, T. Wilkman, A. Kiukkonen, J. Leikola, P. Stoor, 2019, pp. 1072-1076.

[31] R. Konradi, C. Acikgoz, M. Textor, Macromolecular rapid communications, 33 (2012) 16631676.

[32] S. Buwalda, B. Nottelet, A. Bethry, R.J. Kok, N. Sijbrandi, J. Coudane, Journal of colloid and interface science, 535 (2019) 505-515.

[33] L.A.L. Fliervoet, M. Najafi, M. Hembury, T. Vermonden, Macromolecules, 50 (2017) 83908397.

[34] K. Matyjaszewski, Macromolecules, 45 (2012) 4015-4039.

[35] M.H. Stenzel, Chemical Communications, (2008) 3486-3503.

[36] A. Jain, L.S. Duvvuri, S. Farah, N. Beyth, A.J. Domb, W. Khan, Advanced Healthcare Materials, 3 (2014) 1969-1985.

[37] S. El Habnouni, J.-P. Lavigne, V. Darcos, B. Porsio, X. Garric, J. Coudane, B. Nottelet, Acta biomaterialia, 9 (2013) 7709-7718.

[38] S.R. Benhabbour, H. Sheardown, A. Adronov, Macromolecules, 41 (2008) 4817-4823.

[39] B. Dong, S. Manolache, A.C.L. Wong, F.S. Denes, Polymer Bulletin, 66 (2011) 517-528.

[40] C. Xu, S.E. Barnes, T. Wu, D.A. Fischer, D.M. DeLongchamp, J.D. Batteas, K.L. Beers, Advanced Materials, 18 (2006) 1427-1430.

[41] E. Berndt, S. Behnke, M. Ulbricht, 2011, pp. 2379-2390. 


\section{Table of Contents Graphic}

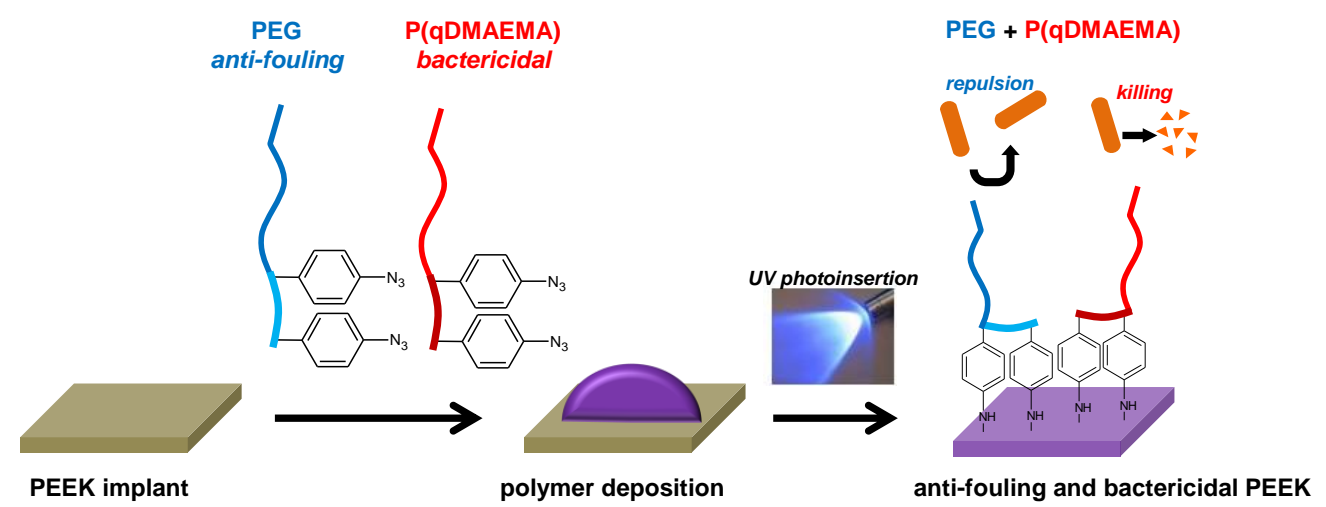

